\title{
Aphorisms about learning
}

\author{
Marshall L. Jacobs, MD
}

\author{
From the Division of Cardiac Surgery, The Johns Hopkins Medical Institutions, Baltimore, Md. \\ Disclosures: Author has nothing to disclose with regard to commercial support. \\ Received for publication March 28, 2017; accepted for publication March 30, 2017; available ahead of print May \\ $2,2017$. \\ Address for reprints: Marshall L. Jacobs, MD, Division of Cardiac Surgery, The Johns Hopkins Hospital, Zayed \\ 7107, 1800 Orleans St, Baltimore, MD 21287 (E-mail: marshall.jacobs@comcast.net). \\ J Thorac Cardiovasc Surg 2017;154:203-4 \\ $0022-5223 / \$ 36.00$ \\ Copyright (c) 2017 by The American Association for Thoracic Surgery \\ http://dx.doi.org/10.1016/j.jtcvs.2017.03.131
}

“"It's What We Think We Know That Keeps Us From Learning!'-Claude Bernard" is a thoughtful essay by Ali $\mathrm{N}$. Ibrahimiye ${ }^{1}$ in this issue of the Journal. It is one of a series of articles that make up the Journal's Young Editor Series. For the title, Ibrahimiye has chosen an aphorism attributed to the 19th century French physiologist Claude Bernard, who had initially sought success in drama and literature before making the transition from playwright to student of medicine. Bernard went on to become a prodigious investigator of mammalian and human physiology whose stated objective was to establish the use of the scientific method in medicine. Among the many areas of discovery in which he left his mark were the role of the pancreas in digestion, the role of the liver in glycogen synthesis and breakdown, and the complex relationship between nerves and the circulatory system that account for "vasomotor" phenomena.

Ibrahimiye has used the statement attributed to Bernard as a springboard to discuss the various ways in which an individual can "continue to learn after formal training." He has divided that learning experience into four domains. Of these, which include structured continuing medical education, clinical practice (learning from patients), learning by teaching, and learning from mentors, Ibrahimiye $^{1}$ places greatest emphasis on the last of the four. He concludes, correctly in my opinion, that a young surgeon's ongoing education is dependent on "the right attitude and a capable mentor who is willing to invest" in the younger surgeon's growth and development. It is difficult to argue with that.

But our 19th century soothsayer Claude Bernard might take things a step further. In his 1865 major discourse on the scientific method, An Introduction to the Study of Experimental Medicine, Bernard ${ }^{2}$ delved into the nature of knowledge and its acquisition-the process of discovery, or more simply "how we learn." He examined the tension inherent in the relationship between authority and observation. "When we meet a fact which contradicts a prevailing theory, we must accept the fact and abandon the theory, even when the theory is supported by great names and generally accepted," Bernard ${ }^{2}$ said. In no way does this detract from the importance of the facts and theories

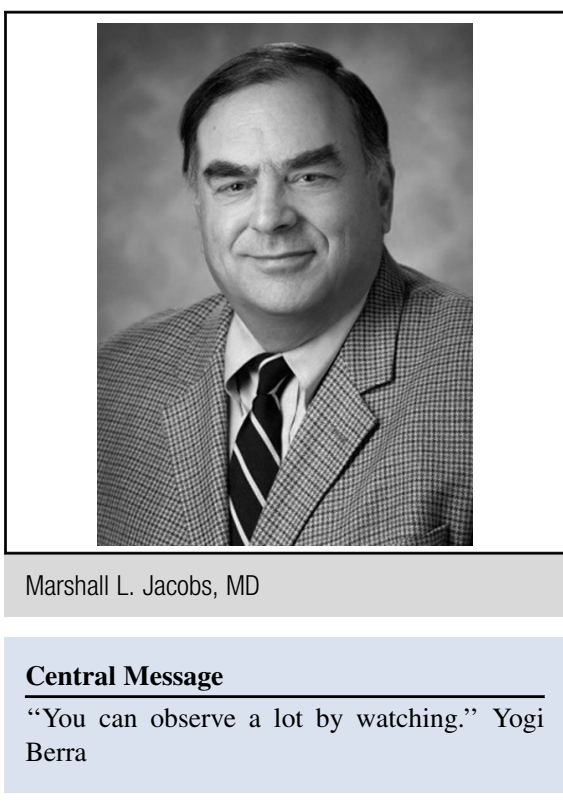

See Article page 200.

proffered by one's mentors. It suggests, however, that the most fundamental and reliable method of learning is through observation.

In the field of cardiothoracic surgery, learning encompasses more than acquisition of knowledge. More, even, than the attainment of wisdom. It is about becoming effective. This does depend, of course, on a solid foundation of factual knowledge-but also on the cultivation of habits of observation, reflection, synthesis, action, and reaction. And it all begins, of course, with observation. John Kirklin captured the essence of the effective surgeon's unique qualities in his statement, "At a given instant everything the surgeon knows suddenly becomes important to the solution of the problem. You can't do it an hour later, or tomorrow. Nor can you go to the library and look it up." 3 To be effective, a surgeon must catalog countless observations, and be able to synthesize and act, often "at a given instant."

And while we are on the subject of aphorisms attributed to great men who have expounded on the process of learning, let's not overlook one of many aphorisms widely attributed to famous 20th century philosopher of the New York school, Larry "Yogi" Berra. "You can observe a lot by watching."

Ibrahimiye's emphasis ${ }^{1}$ on the importance of a young surgeon finding a good mentor when seeking a first job after residency training is undoubtedly valid, and his 
advice is sound. But the success of mentorship depends on processes of continuous observation and "active absorption" on the part of the younger surgeon, while both the mentor and the mentee continue to engage in learning.

\section{References}

1. Ibrahimiye AN. "It's what we think we know that keeps us from learning!"-Claude Bernard. J Thorac Cardiovasc Surg. 2017:154:200-2.

2. Bernard C. An introduction to the study of experimental medicine (Dover Books on Biology). Green HC, trans. New York: Dover: Dover edition; 1957. p.164.

3. Surgery: the best hope of all. TIME Magazine. May 3, 1963. 